\title{
Transcutaneous Carbon Dioxide Treatment Is Capable of Reducing Peripheral Vascular Resistance in Hypertensive Patients
}

\author{
BALÁZS NÉMETH ${ }^{1,2}$, ISTVÁN KISS ${ }^{1}$, BELLA AJTAY $^{1}$, IVÁN PÉTER ${ }^{2}$, ZITA KRESKA $^{2}$, \\ ATTILA CZIRÁKI ${ }^{3}$, IVÁN G. HORVÁTH ${ }^{3}$ and ZÉNÓ AJTAY ${ }^{2,3}$ \\ ${ }^{1}$ Department of Public Health Medicine, and ${ }^{3}$ Heart Institute, Medical School, University of Pécs, Pécs, Hungary; \\ ${ }^{2}$ Zsigmondy Vilmos SPA Hospital, Harkány, Hungary
}

\begin{abstract}
Aim: We aimed to investigate the effects of a single carbon dioxide $\left(\mathrm{CO}_{2}\right)$ treatment on arterial stiffness by monitoring the changes of aortic pulse-wave velocity $(P W V)$ and aortic augmentation index (AIXao), which are indicators of arterial stiffness. Patients and Methods: PWV and AIXao were measured by an invasively validated oscillometric device. The measurements of stiffness parameters were performed before the $\mathrm{CO}_{2}$ treatment, and at 1, 4 and $8 \mathrm{~h}$ after the first treatment. Results: Thirty-one patients were included. No significant changes were found in PWV. AIXao decreased significantly $1 \mathrm{~h}$ and $4 \mathrm{~h}$ after $\mathrm{CO}_{2}$ treatment compared to baseline values $(p=0.034$ and $p<0.001)$. AIXao increased $8 \mathrm{~h}$ after the $\mathrm{CO}_{2}$ treatment, but remained significantly lower than baseline AIXao values $(p=0.016)$. Conclusion: $\mathrm{CO}_{2}$ treatment is capable of reducing peripheral vascular resistance. We hypothesize that $\mathrm{CO}_{2}$ is not only a temporal vasodilator but is also capable of activating vasodilation pathways.
\end{abstract}

The transcutaneous administration of carbon dioxide $\left(\mathrm{CO}_{2}\right)$, further referred to as ' $\mathrm{CO}_{2}$ treatment', has been used for curative purposes for decades. The first article investigating the medicinal use of $\mathrm{CO}_{2}$ was published by Brandi et al. in 1932 (1). $\mathrm{CO}_{2}$ passes freely through membranes and has a well-known vasodilation effect. Both in vitro and in vivo studies have demonstrated a rightward shift of the oxygenhemoglobin dissociation curve after administration of $\mathrm{CO}_{2}$.

This article is freely accessible online.

Correspondence to: Balázs Németh, Department of Public Health Medicine, Medical School, University of Pécs, Szigeti str. 12. H-7624 Pécs, Hungary. Tel: +36 72536394, e-mail: balazs.nemeth@aok.pte.hu

Key Words: Carbon dioxide therapy, aortic pulse-wave velocity, aortic augmentation index, aortic stiffness.
Sakai et al. described this as an "artificial Bohr-effect". This was responsible for the increased partial pressure of oxygen and the decreased $\mathrm{pH}$ which were shown in vivo (2). The findings of Minamiyama and Yamamoto confirmed these effects by using intra-vital microscopy video imaging to demonstrate subcutaneus vasodilation after $\mathrm{CO}_{2}$ administration. In addition, $\mathrm{CO}_{2}$ was shown to increase the blood flow rate in the observed subcutaneus vessels (3). $\mathrm{CO}_{2}$ treatment is used to cure several diseases such as peripheral arterial and venous disorders (e.g. claudication, and lower limb ulcer), heart diseases (e.g. hypertension, and heart failure) and immunological disorders (e.g. Raynaud's syndrome) $(4,5)$. The pathophysiological link between these conditions is the presence of excessive oxidative stress.

The evidence of the relation between $\mathrm{CO}_{2}$ treatment and oxidative stress is limited. However, Veselá and Wilhelm found $\mathrm{CO}_{2}$ to play a protective role in scavenging free radicals and suppressing oxidative metabolism (6). A recent study demonstrated that $\mathrm{CO}_{2}$ treatment is capable of reducing the level of asymmetric dimethylarginine, which is a marker of oxidative stress (7). Another study suggested that the transcutaneous application of $\mathrm{CO}_{2}$ could have therapeutic effects on muscle atrophy (8). In short, $\mathrm{CO}_{2}$ treatment is a non-invasive, highly effective, low-cost treatment capable of easing the symptoms of arterial and venous diseases possiblg due vasodilatation and reduction of oxidative stress. However, there is no evidence of changes in vascular status after $\mathrm{CO}_{2}$ treatment as far as we are aware.

Aortic pulse-wave velocity (PWV) and aortic augmentation index (AIXao) are widely used and recognized indicators of arterial stiffness $(9,11)$. Studies indicated that PWV is an independent predictor of primary coronary events (12) and fatal stroke (13) among hypertensive patients. AIXao is correlated with the degree of coronary artery disease (14), and predicts mortality in patients with end-stage renal failure (15). Moreover, according to Van Trijp et al., 
AIXao can be used as tool for estimation of coronary heart disease risk, especially among young adults (16).

The aim of this study was to investigate the effects of a single $\mathrm{CO}_{2}$ treatment on arterial stiffness by monitoring the changes of PWV and AIXao.

\section{Patients and Methods}

Study design. The present study was performed at our ISO 9001accredited Cardiology Rehabilitation Inpatient Unit from April 2017 to December 2017. Non-smoker, abstinent from alcohol, hypertensive patients were enrolled. Patients who had previously received $\mathrm{CO}_{2}$ treatment were excluded. Moreover, patients who had suffered from myocardial infarction, stroke or undergone open surgery less than a year before the study were also excluded. Additionally, individuals diagnosed with any kind of cancer or kidney injury were also excluded. Informed written consent was obtained from every patient. This patient selection protocol was used in a previous study investigating the effects of $\mathrm{CO}_{2}$ treatment on the nitric oxide system (7).

PWV and AIXao were measured by an invasively validated oscillometric device according to the manufacturer's protocol (Arteriograph; TensioMed Kft., Budapest, Hungary) (17). This programmable device is capable of measuring PWV and AIXao simultaneously using a special upper arm cuff which is fitted with a pressure sensor. All of the involved individuals were attending a 3-week-long cardiac rehabilitation.

Measurements were performed before the $\mathrm{CO}_{2}$ treatment (baseline), and at 14 and 8 hours after the treatment. $\mathrm{CO}_{2}$ gas was administered for 35 minutes in a plastic bag sealed at mid-thoracic level, as previously described by Fabry et al. (4). The measurements of stiffness parameters were performed in sitting position from 8 a.m. to 18 p.m. The patients did not receive any medication besides their regular antihypertensive drugs during the measurements.

The study protocol was approved by the Regional Ethics Committee of University of Pécs, Pécs, Hungary (Permission No. 5919), in accordance with the 2008 Helsinki declaration.

Statistical analysis. Statistical analysis was performed by IBM SPSS Statistics for Windows Version 22 (IBM Corp., New York, NY, USA). According to Shapiro-Wilk test, PWV and AIXao samples were normally distributed and, thus, were used to demonstrate results (95\% confidence interval for mean). Differences during the follow-up were investigated by paired-sample $t$-test. Independent sample $t$-test was used to compare the stiffness parameters between diabetic patients and non-diabetic patients. Pearson's correlation test was used to reveal correlations. All $p$-values less than 0.05 were considered statistically significant.

\section{Results}

Initially, 35 patients were enrolled. Two patients were excluded because they did not tolerate the upper arm cuff for 8 hours. Due to technical reasons, only baseline values were recorded in the case of two patients; thus they were also excluded. Finally, the stiffness parameters of 31 patients were measured (18 male and 13 female; mean age $=66.7 \pm 9.4$ years).
Table I. Clinical characteristics of the study participants $(n=31)$.

\begin{tabular}{lc}
\hline Characteristic & Value \\
\hline Mean \pm SD age, years & $66.7 \pm 9.4$ \\
Male, $\mathrm{n}(\%)$ & $18(58)$ \\
Mean BMI \pm SD, $\mathrm{kg} / \mathrm{m}^{2}$ & $28.5 \pm 4.7$ \\
Diabetes type $2, \mathrm{n}(\%)$ & $11(35)$ \\
MI, n (\%) & $4(13)$ \\
$\mathrm{CABG}, \mathrm{n}(\%)$ & $9(29)$ \\
$\mathrm{EF},(\%)$ & $56.4 \pm 7.3$ \\
Mean $\mathrm{WBC}$ count $\pm \mathrm{SD}, \times 10^{9} / 1$ & $5.97 \pm 1.77$ \\
\hline
\end{tabular}

BMI: Body mass index; MI: myocardial infarction; CABG: coronary artery bypass surgery; EF: ejection fraction; WBC: white blood cell count.

Table II. Detailed results of the monitored parameters of the study participants $(n=31)$.

\begin{tabular}{lcccc}
\hline & Baseline & $1 \mathrm{~h}$ & $4 \mathrm{~h}$ & $8 \mathrm{~h}$ \\
\hline $\mathrm{AIXaO} \pm \mathrm{SD},(\%)$ & $35.82 \pm 11.67$ & $31.41 \pm 8.91$ & $27.79 \pm 9.37$ & $30.9 \pm 8.04$ \\
$\mathrm{PVW} \pm \mathrm{SD},(\mathrm{m} / \mathrm{s})$ & $9.52 \pm 2.12$ & $8.91 \pm 2.43$ & $8.89 \pm 2.01$ & $9.39 \pm 2.66$ \\
$\mathrm{SBP} \pm \mathrm{SD},(\mathrm{mmHg})$ & $125 \pm 12$ & $123 \pm 14$ & $119 \pm 7$ & $119 \pm 8$ \\
$\mathrm{DBP} \pm \mathrm{SD},(\mathrm{mmHg})$ & $72 \pm 8$ & $70 \pm 11$ & $68 \pm 7$ & $67 \pm 6$ \\
\hline
\end{tabular}

AIXao: Aortic augmentation index; PWV: aortic pulse wave velocity; SBP: systolic blood pressure; DBP diastolic blood pressure.

Clinical characteristics of the participants are shown in Table I.

Regarding the PWV, no significant changes were found when comparing the baseline PWV to values at 1 hour $(p=0.097), 4$ hours $(p=0.055)$ or 8 hours $(p=0.785)$ after $\mathrm{CO}_{2}$ treatment. Changes of the PWV after $\mathrm{CO}_{2}$ treatment are shown in Figure 1.

AIXao decreased significantly 1 hour after the $\mathrm{CO}_{2}$ treatment compared to the baseline values $(p=0.034)$. Four hours after the treatment, AIXao decreased further and remained significantly lower compared to baseline $(p<0.001)$. Finally, AIXao started to increase 8 hours after the $\mathrm{CO}_{2}$ treatment but still remained significantly lower than baseline values $(p=0.016)$. Changes of AIXao after $\mathrm{CO}_{2}$ treatment are shown in Figure 2.

No significant differences were found between baseline AIXao and AIXao measured 1, 4 and 8 hours after treatment among patients suffering from diabetes mellitus $(p=0.955$, $p=0.077$ and $p=0.581$, respectively).

Detailed results of the monitored parameters are shown in Table II.

None of the baseline medications (angiotensin-converting enzyme inhibitors (ACEIs), angiotensin II receptor blockers (ARBs), beta-receptor blockers, statins, diuretics, antidiabetics, antiplatelet treatment, proton pump inhibitors, H2-receptor blockers) showed no effect on stiffness parameters. 


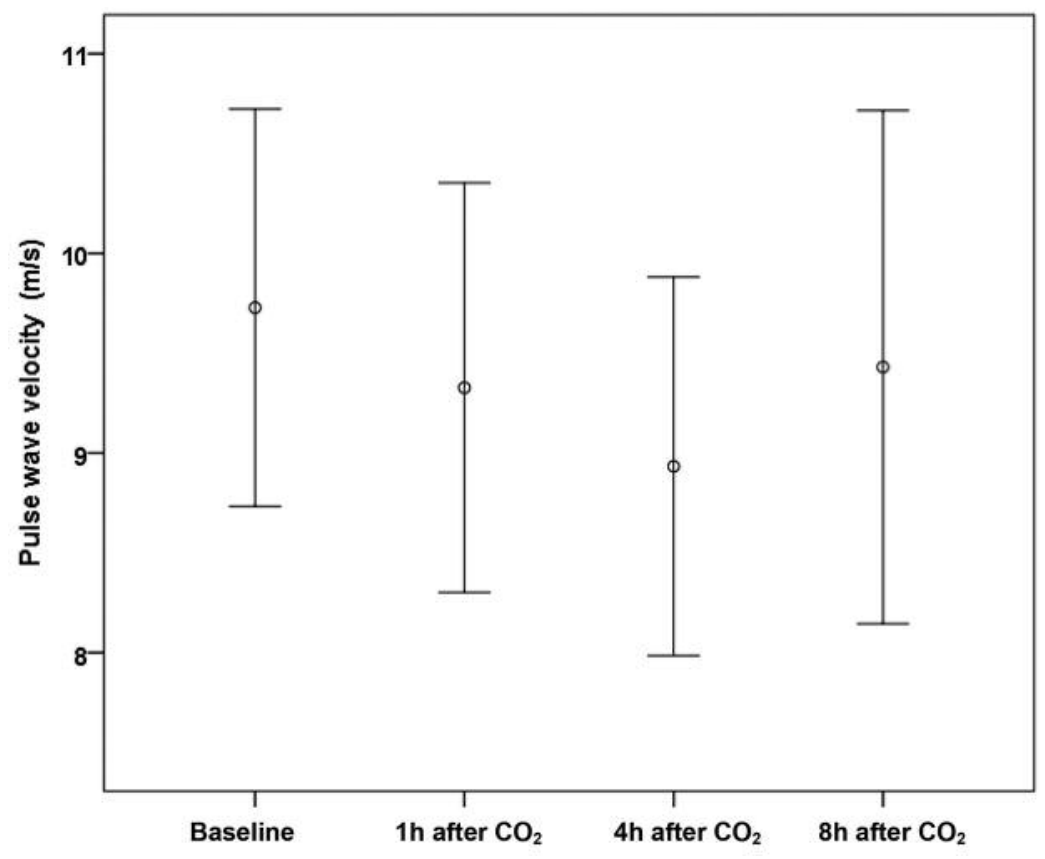

Figure 1. Pulse wave velocity before and after $\mathrm{CO}_{2}$ treatment.

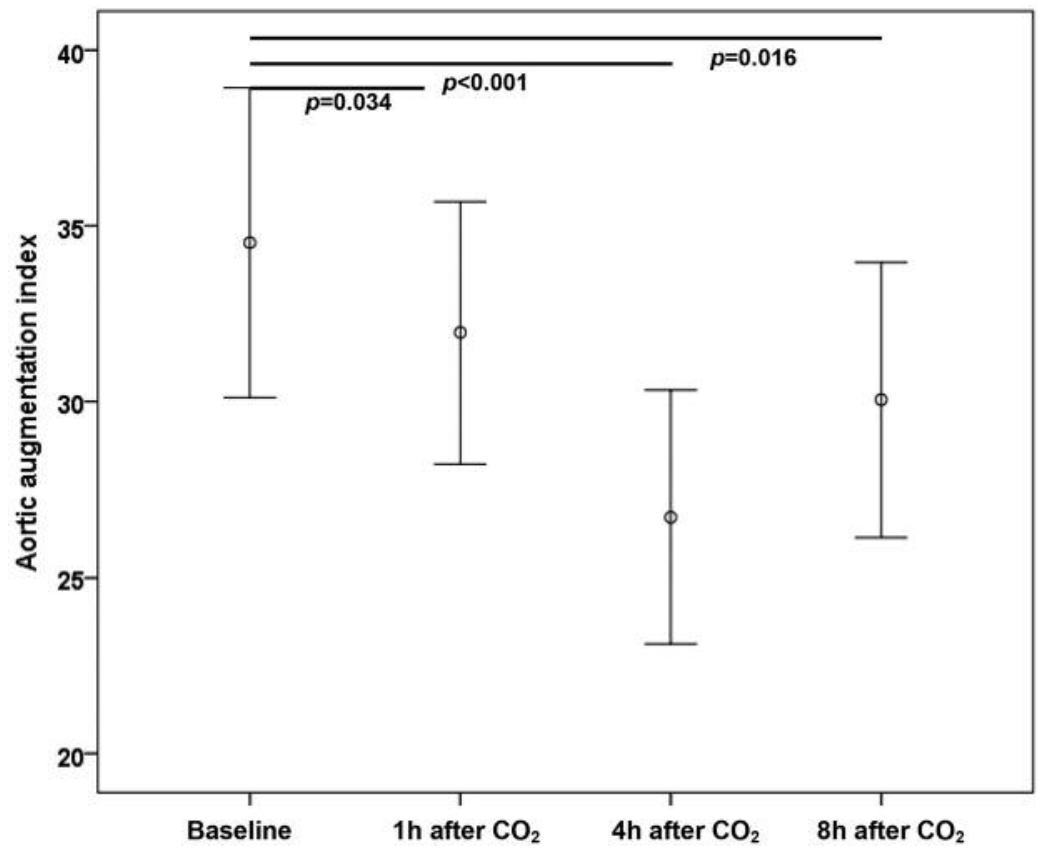

Figure 2. Aortic augmentation index after $\mathrm{CO}_{2}$ treatment.

\section{Discussion}

To the best of our knowledge, this is the first study investigating the changes of arterial stiffness (PWV and AIXao) parameters after a single $\mathrm{CO}_{2}$ treatment.
Aortic stiffness develops because the elastic fibers of the aorta are replaced by collagen fibers (18). This histopathological change is represented by the speed of the PWV. The stiffening of the aorta is a slow procedure; significant changes require years. Taking this into account, 
it is not surprising that a single $\mathrm{CO}_{2}$ treatment did not significantly change the PWV. On the other hand, AIXao represents the tone of small arterioles. Accordingly, the changes of the AIXao can be regarded as changes of peripheral vascular resistance $(15,19)$. The main result of this study is that even a single 35-minute-long $\mathrm{CO}_{2}$ treatment is capable of reducing AIXao significantly. AIXao decreased almost instantly after the $\mathrm{CO}_{2}$ treatment. However, AIXao started to increase 8 hours after the $\mathrm{CO}_{2}$ treatment but still remained significantly lower than the baseline AIXao value. This relatively quick change of peripheral resistance can be explained by the physical properties of $\mathrm{CO}_{2}$. Interestingly, the most pronounced effect of $\mathrm{CO}_{2}$ treatment on the peripheral resistance developed 4 hours after the treatment. This indicates that transcutaneusly applied $\mathrm{CO}_{2}$ is not only a temporal vasodilator but it is capable of activating endogenous pathways leading to vasodilatation. The results of our previous study partly confirmed this hypothesis. Our study showed that $\mathrm{CO}_{2}$ treatment has beneficial effects on the NO pathway (7). NO-related vasodilatation may be an explanation for the delayed response of AIXao.

In line with the study of Zhang et al., no differences were found when comparing the stiffness parameters of diabetic patients with those of the non-diabetic patients (20). Another interesting result of this study is that the above-mentioned changes of AIXao were not demonstrable in patients suffering from diabetes mellitus. The vascular system of diabetic patients seems to be less responsive to the beneficial effects of $\mathrm{CO}_{2}$ treatment; this is most likely due to the well-known micro- and macrovascular complications of diabetes (21).

According to previous studies, angiotensin-converting enzyme inhibitors, angiotensin II receptor blockers and statins have been shown to improve PWV and AIXao values (22-25). These beneficial effects were not demonstrable in our patients, probably due to the small sample size.

Study limitations. The lack of a control group can be addressed as a limitation. However, the aim of this study was only to demonstrate the effects of a single $\mathrm{CO}_{2}$ treatment on stiffness parameters. Moreover, the effectiveness of $\mathrm{CO}_{2}$ treatment has been proven by other studies $(1-5,7)$.

\section{Conclusion}

Our study suggests that even a single $\mathrm{CO}_{2}$ treatment is capable of reducing peripheral vascular resistance. Furthermore, because of the 4-hour delay in AIXao change observed have, we hypothesize that $\mathrm{CO}_{2}$ is not only a temporal vasodilator but is also capable of activating endogenous pathways leading to vasodilatation. However, further larger studies are necessary to confirm our hypothesis and to describe the beneficial effects of $\mathrm{CO}_{2}$ treatment.

\section{Conflicts of Interest}

The Authors declare that there is no conflict of interests regarding the publication of this article.

\section{Acknowledgements}

The Authors would like to thank all the nurses of the Cardiology ward for their invaluable help. The present scientific contribution is dedicated to the 650th anniversary of the foundation of the University of Pécs, Hungary. Balázs Németh was supported by the ÚNKP-18-3-III New National Excellence Program of the Ministry of Human Capacities, Hungary (http://www.kormany.hu/hu/emberieroforrasok-miniszteriuma). The funder had no role in study design, data collection and analysis, decision to publish, or preparation of the article. The publication of this manuscript was supported by the "EFOP-3.6.3-VEKOP-16-2017-00009" grant.

\section{References}

1 Brandi C, Aniello CD, Grimaldi L, Bosi B, Dei I, Lattarulo P and Alessandrini $\mathrm{C}$ : Carbon dioxide therapy in the treatment of localized adiposities: Clinical study and histopathological correlations. Aesthetic Plast Surg 25: 170-174, 2001.

2 Sakai Y, Miwa M, Oe K, Ueha T, Koh A, Niikura T, Iwakura T, Lee SY, Tanaka M and Kurosaka M: A novel system for transcutaneous application of carbon dioxide causing an "Artificial Bohr Effect" in the human body. PLoS One 6: e24137, 2011.

3 Minamiyama $M$ and Yamamoto A: Direct evidence of the vasodilator action of carbon dioxide on subcutaneous microvasculature in rats by use of intra-vital. J Biorheol 24: 42-46, 2010.

4 Fabry R, Monnet P, Schmidt J, Lusson JR, Carpentier PH, Baguet JC and Dubray C: Clinical and microcirculatory effects of transcutaneous $\mathrm{CO}_{2}$ therapy in intermittent claudication. Randomized double-blind clinical trial with a parallel design. Vasa 38: 213-224, 2009.

5 Schmidt J, Monnet P, Normand B and Fabry R: Microcirculatory and clinical effects of serial percutaneous application of carbon dioxide in primary and secondary Raynaud's phenomenon. Vasa 34: 93-100, 2005.

6 Veselá A and Wilhelm $\mathrm{J}$ : The role of carbon dioxide in free radical reactions of the organism. Physiol Res 51: 335-339, 2002.

7 Németh B, Kiss I, Jencsik T, Péter I, Kereska Z, Kőszegi T, Miseta A, Kustán P, Boncz I, Laczo A and Ajtay Z: Angiotensin-converting enzyme inhibition improves the effectiveness of transcutaneous carbon dioxide treatment. In Vivo 31(3): 425-428, 2017.

8 Nishimoto H, Inui A, Ueha T, Inoue M, Akahane S, Harada R, Mifune Y, Kokubu T, Nishida K, Kuroda R and Sakai Y: Transcutaneous carbon dioxide application with hydrogel prevents muscle atrophy in a rat sciatic nerve crush model. J Orthop Res 36(6): 1653-1658, 2018.

9 Mancia G, Fagard R, Narkiewicz K, Redón J, Zanchetti A, Böhm M, Christiaens T, Cifkova R, De Backer G, Dominiczak A, Galderisi M, Grobbee DE, Jaarsma T, Kirchhof P, Kjeldsen SE, Laurent S, Manolis AJ, Nilsson PM, Ruilope LM, Schmieder RE, Sirnes PA, Sleight P, Viigimaa M, Waeber B, Zannad F and Task Force Members: 2013 ESH/ESC Guidelines for the management of arterial hypertension: The Task Force for the management of arterial hypertension of the European Society 
of Hypertension (ESH) and of the European Society of Cardiology (ESC). J Hypertens 31(7): 1281-357, 2013.

10 Vlachopoulos C, Xaplanteris P, Aboyans V, Brodmann M, Cífková R, Cosentino F, De Carlo M, Gallino A, Landmesser U, Laurent S, Lekakis J, Mikhailidis DP, Naka KK, Protogerou AD, Rizzoni D, Schmidt-Trucksäss A, Van Bortel L, Weber T, Yamashina A, Zimlichman R, Boutouyrie P, Cockcroft J, O'Rourke M, Park JB, Schillaci G, Sillesen H and Townsend RR: The role of vascular biomarkers for primary and secondary prevention. A position paper from the European Society of Cardiology Working Group on peripheral circulation: Endorsed by the Association for Research into Arterial Structure and Physiology (ARTERY) Society. Atherosclerosis 241(2): 507-532, 2015.

11 Sehestedt T, Jeppesen J, Hansen TW, Rasmussen S, Wachtell K, Ibsen $\mathrm{H}$, Torp-Pedersen $\mathrm{C}$ and Olsen $\mathrm{MH}$ : Thresholds for pulse wave velocity, urine albumin creatinine ratio and left ventricular mass index using SCORE, Framingham and ESH/ESC risk charts. J Hypertens 30(10): 1928-1936, 2012.

12 Boutouyrie P, Lacolley P, Briet M, Regnault V, Stanton A, Laurent S and Mahmud A: Pharmacological modulation of arterial stiffness. Drugs 71(13): 1689-1701, 2011.

13 Laurent S, Katsahian S, Fassot C, Tropeano AI, Gautier I, Laloux B and Boutouyrie P: Aortic stiffness is an independent predictor of fatal stroke in essential hypertension. Stroke 34(5): 1203-1206, 2003.

14 Weber T, Auer J, O'rourke MF, Kvas E, Lassnig E, Lamm G, Stark N, Rammer M and Eber B: Increased arterial wave reflections predict severe cardiovascular events in patients undergoing percutaneous coronary interventions. European Heart Journal 26(24): 2657-2663, 2005 .

15 London GM, Blacher J, Pannier B, Guérin AP, Marchais SJ and Safar ME: Arterial wave reflections and survival in end-stage renal failure. Hypertension 38(3): 434-438, 2001.

16 Van Trijp MJ, Uiterwaal CS, Bos WJ, Oren A, Grobbee DE and Bots ML: Noninvasive arterial measurements of vascular damage in healthy young adults: Relation to coronary heart disease risk. Ann Epidemiol 16: 71-77, 2006.

17 Horváth IG, Németh A, Lenkey Z, Alessandri N, Tufano F, Kis P, Gaszner B and Cziráki A: Invasive validation of a new oscillometric device (Arteriograph) for measuring augmentation index, central blood pressure and aortic pulse wave velocity. $\mathbf{J}$ Hypertens 28(10): 2068-2075, 2010.
18 O'Rourke MF and Nichols WW: Aortic diameter, aortic stiffness, and wave reflection increase with age and isolated systolic hypertension. Hypertension 45: 652-658, 2004.

19 Janner JH, Godtfredsen NS, Ladelund S, Vestbo J and Prescott E: Aortic augmentation index: reference values in a large unselected population by means of the SphygmoCor device. Am J Hypertension 23(2): 180-185, 2010.

20 Zhang M, Bai Y, Ye P, Luo L, Xiao W, Wu H and Liu D: Type 2 diabetes is associated with increased pulse wave velocity measured at different sites of the arterial system but not augmentation index in a Chinese population. Clin Cardiol 34(10): 622-627, 2011.

21 Fowler MJ: Microvascular and Macrovascular Complications of Diabetes. Clinical Diabetes 26: 77-82, 2008.

22 Mallareddy M, Parikh Cr and Peixoto Aj: Effect of angiotensinconverting enzyme inhibitors on arterial stiffness in hypertension: systematic review and meta-analysis. J Clin Hypertens 8: 398-403, 2006.

23. Manisty C, Mayet J, Tapp Rj, Sever PS, Poulter N, McG Thom SA, Hughes AD and ASCOT Investigators: Atorvastatin treatment is associated with less augmentation of the carotid pressure waveform in hypertension: A substudy of the AngloScandinavian Cardiac Outcome Trial (ASCOT). Hypertension 54: 1009-1013, 2009.

24 Doi M, Miyoshi T, Hirohata S, Kamikawa S, Usui S, Kaji Y, Sakane K, Ogawa H, Ninomiya Y and Kusachi S: Combination therapy of calcium channel blocker and angiotensin II receptor blocker reduces augmentation index in hypertensive patients. Am J Med Sci 339: 433-439, 2010.

25 Boutouyrie P, Tropeano AI, Asmar R, Gautier I, Benetos A, Lacolley $\mathrm{P}$ and Laurent $\mathrm{S}$ : Aortic stiffness is an independent predictor of primary coronary events in hypertensive patients: a longitudinal study. Hypertension 39: 10-15, 2002.
Received August 30, 2018

Revised September 20, 2018

Accepted September 21, 2018 